\title{
Endometrial stromal sarcoma- A case report
}

\author{
Geetha ${ }^{1}$, Rathika. $\mathbf{R}^{2 *}$ \\ ${ }^{\mathbf{1}}$ Associate Professor, ${ }^{\mathbf{2} J u n i o r ~ R e s i d e n t, ~}{ }^{\mathbf{1}, \mathbf{2}}$ Dept. of Obstetrics Gynaecology, ${ }^{\mathbf{1 , 2}}$ Vinayaka Mission's Medical College and Hospital, Karaikal, \\ Pondicherry, India
}

\section{Correspondence Author: Rathika. R}

Email: rathikar.rajesh@yahoo.com

Received: $4^{\text {th }}$ March, 2019

Accepted: $22^{\text {ed }}$ March, 2019

\begin{abstract}
Endometrial stromal sarcomas are rare malignant tumours of the uterus. Most details about this tumour is obtained from previous case reports. In most of the cases, diagnosis is made only postoperatively. A 29 year old female, came with complaints of heavy menstrual bleeding, lower abdominal pain, mass in lower abdomen for 2 months. Clinical examination and investigations showed bulky irregularly enlarged uterus probably Fibroid Uterus. Patient was planned for Myomectomy. Intraoperatively, uterus was irregularly enlarged with cauliflower like growth of size 7 × $5 \mathrm{~cm}$ over fundus suggestive of Carcinoma. Total abdominal hysterectomy with bilateral salphingo oophorectomy with bilateral pelvic lymphnode dissection with infracolic omentectomy was done. Histopatholgy examination revealed as Low Grade Endometrial Stromal Sarcoma with Negative Lymph Node Spread. Postoperatively, Patient was evaluated for ER sensitivity and started on Tab. Anastrazole.
\end{abstract}

Keywords: Uterine sarcoma, Endometrial stromal sarcoma, Malignant uterine tumour

\section{Introduction}

Endometrial stromal sarcomas constitute around $0.2 \%$ of all uterine malignancies. They constitute second most common mesenchymal uterine tumours. It usually involves age group of 40-58 years and most women are premenopausal. World health organisation classifies ESS into 1) Endometrial Stromal Nodule 2)Low Grade ESS 3) High Grade ESS 4)Undifferentiated ESS. It usually presents late with local metastasis. Distant metastasis can occur even 20 years after initial diagnosis. Surgery and hormonal therapy are mainstay of treatment. Prognosis is good in case of early diagnosis.

\section{Case Report}

A 29 year old female was admitted in Department of Obstetrics and Gynaecology, Vinayaka Missions Medical College and Hospital, Karaikal, Pondicherry with complaints of heavy menstrual bleeding, lower abdominal pain, mass in lower abdomen for 2 months. Clinical examination revealed uterus enlarged upto 14-16 weeks size, firm, mobile from side to side, irregular margins with irregular surface. Ultrasonogram of abdomen showed uterus of size $10.3 * 8.0 * 7.8 \mathrm{~cm}$, intramural fibroid of size $6.7 * 6 \mathrm{~cm}$ in anterior wall. Patient was planned for Myomectomy. Intraop findings-uterus irregularly enlarged, cauliflower like growth of size $7 \times 5 \mathrm{~cm}$ seen over fundus, edematous right fallopian tube. Bilateral ovaries were cystic and unhealthy. On suspicion of malignancy, Total Abdominal Hysterectomy with Bilateral Salphingo Oophorectomy with Bilateral Pelvic Lymphnode Dissection with Infracolic Omentectomy was done. Histopatholgy examination report came as Low Grade Endometrial Stromal Sarcoma with Negative Tumour Deposit. Patient underwent Immunohistiochemistry studies and found to be ER positive. Patient was started on Tab. Anastrazole $1 \mathrm{mg}$ OD. Patient is in regular follow up.
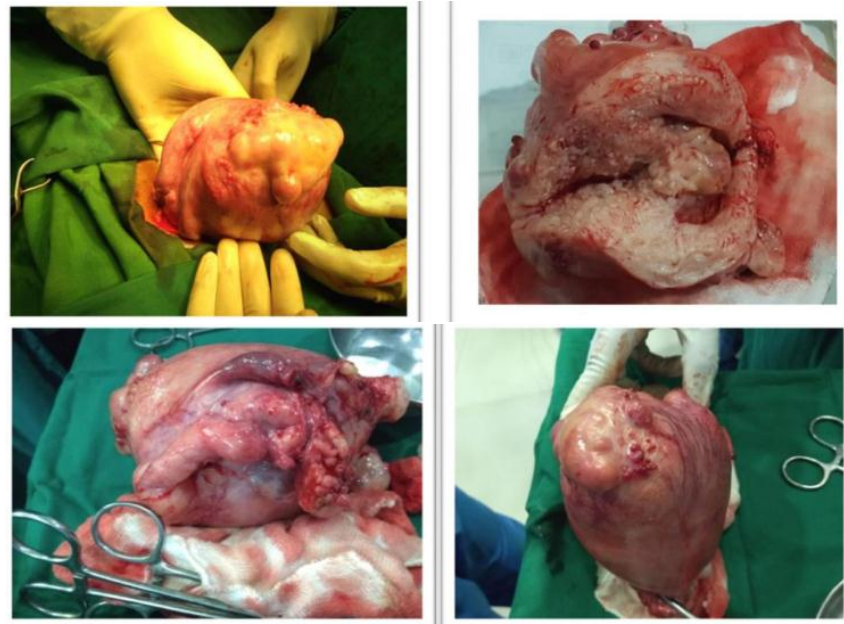

Fig. 1: Endometrial Stromal Sarcoma

\section{Discussion}

Endometrial stromal sarcoma (ESS)is second most common Malignant Pure Mesenchymal Uterine Tumor(MPMUT) constituting about $0.2 \%$ of all uterine tumours. ${ }^{1}$ It arises from submesothelial pleuripotent mullerian cells. ${ }^{2}$ ESS is classified into i)Endometrial Stromal Nodule(ESN) ii)Low Grade ESS(LGESS) iii)High Grade ESS iv)Undifferentiated ess (UES). ${ }^{3}$ Cytogenetic Abnormality of ESS is recurrent translocation $\mathrm{t}(7 ; 17)(\mathrm{p} 15 ; \mathrm{q} 21) .{ }^{4}$ Low grade tumours are indolent tumours with favorable prognosis. ${ }^{5}$ LGESS occurs in age group of 28-67 years and presents as uterine enlargement, pelvic mass, abnormal uterine bleeding. ${ }^{6}$ High grade tumours have features intermediate between LGESS and UES. ${ }^{7}$ Microscopically, HGESS have round cells with spindle cell fibromyxoid component. ${ }^{6}$ Undifferentiated ESS usually present as postmenopausal bleeding. UES are highly aggressive and carry poor prognosis. ${ }^{8}$ ESS is common in extrauterine sites also. Among them, ovary is first involved usually $76 \%$,extragonadal sites constitute $24 \% .^{9}$ Histology of extrauterine extraovarian ESS show multinodular growth 
patterns. ${ }^{10}$ Imaging studies of ESS are usually nonspecific. ${ }^{11}$ Positive labelling for CD10, PR, ER with negativity for CD117,CD34 is confirmative diagnosis. ${ }^{12}$ Mainstay of treatment is total abdominal hysterectomy with bilateral salphingo oophorectomy. In case of pregnancy associated with sarcomas, laproscopy can be done safely. ${ }^{13}$ Abdominal surgery can also be done safely in case of pregnancy associated ESS. ${ }^{14}$ In case of inoperable, recurrent tumours, hormonal therapy is helpful. It includes medroxyprogesterone acetate, Gnrh agonists, aromatase inhibitors. ${ }^{15}$ In earlier studies, oral medroxyprogesterone acetate was used. ${ }^{16}$ In recent times, combination containing Doxorubicin is used. ${ }^{17}$ Ifosfamide is helpful in chemoresistant sarcomas. $^{18}$ Tamoxifen, estrogens are contraindicated as they cause stimulative effect on disseminated endometrial stromal cells. ${ }^{19}$ Dydrogestrone is hormonally active, non androgenic, synthetic steroid. ${ }^{20}$ It lacks estrogenic, androgenic, glucocorticoid, mineralocorticoid properties. Dydrogestrone is preferred to other progestins due to lack of side effects. ${ }^{21}$ Long term use of Gnrh agonists can cause osteoporosis. ${ }^{22}$ Anastrazole is the preferred aromatase inhibitor. They cause muscle pain, nausea, vomiting. ${ }^{23}$ There is noncompliance of Letrozole while usage in breast cancer patients. ${ }^{24} 5$ year survival rate of patients with stage I and II is $90 \%$,stage III and IV is $50 \%$.Follow up is done once in 3 months for first year, half yearly for next 4 years, thereafter yearly follow up. ${ }^{25}$

\section{Conflict of Interest: None.}

\section{References}

1. D" Angeloe, Prat J. Uterine Sarcomas:A Review. Gynaecological Oncol 2010;116;131-9.

2. Baiocchi G, Kavanagh JJ, Wharton JT. Endometrial Stromal sarcomas arising from ovarian and extraovarian endometriosis:report of two cases and review of literature. Gynaecological Oncol 1990;36:147-51.

3. Oliva E. Cellular mesenchymal tumours of uterus: A review emphasizing recent Observatios. Int J Gynecol Pathol 2014;33:374-384

4. Nucci Mr, Harburger D, Koontz J, Molecular analysis of jazf1-jjaz1 gene fusion by rt pcr and fish in endometrial stromal neoplasms. Am J Surg Pathol 2007;31:65-70.

5. 5.Chang Kl, Crabtree Gs, Lim Tan Sk. Primary uterine endometrial stromal neoplasms. A clinicopatholgic study of 117 cases. Am J Surg Pathol 1990;14:415-38.

6. Lee Ch, Marino-Enriquez A, Ou W. The clinicopathologic features of ywhae-fam 22 endometrial stromal sarcomas: A histologically high-grade and clinically aggressive tumor. Am J surgpathol 2012;36:641-53

7. Kurihara S, Oda Y, Ohishi Y. Endometrial stromal sarcomas and related high-grade Sarcomas: Immunohistochemical and molecular genetic study of 31 cases. Am J Surg Pathol 2008;32:1228-38

8. Tanner EJ, Garg K, Leitao MM Jr. High grade undifferentiated uterine sarcoma: Surgery, treatment, and survival outcomes. Gynecol Oncol 2012;127:27-31.

9. Mourra N, Tiret E, Parc Y, de Saint-Maur P, Parc R, Flejou $\mathrm{JF}$ et al. Endometrial stromal sarcoma of the rectosigmoid colon arising inextragonadal endometriosis and revealed by portal vein thrombosis. Arch Pathol Lab Med 2001;125:1088-90.
10. Kim L, Choi SJ, Park IS, Han JY, Kim JM, Chu YC et al. Endometrial stromal sarcoma of the small bowel. Ann Diagn Pathol 2008;12:128-33

11. Koyama T, Togashi K, Konishi I, Kobayashi H, Ueda H, Kataoka ML et al. MR imaging of endometrial stromal sarcoma: correlation with pathologic findings. AJR Am J Roentgenol 1999;173:767-72.

12. Kim L, Choi SJ, Park IS, Han JY, Kim JM, Chu YC et al. Endometrialstromal sarcoma of the small bowel, Ann Diagn Pathol 12(2008):28 133,http://dx.doi.org/10.1016/j.anndiagpath.2006.03.020.

13. R.P. Masand, E.D. Euscher, M.T. Deavers, A. Malpica, Endometrioidstromalsarcoma: a clinicopathologic study of 63 cases, Am. J. Surg. Pathol. 37(2013)1635-1647.

14. J.A. Rauh-Hain, M.G. del Carmen, Endometrial stromal sarcoma: a systematicreview, Obstet Gynecol 122(2013):676-83.

15. Rizzo AG: Laparoscopic surgery in pregnancy: long-term follow-up. J Laparoendosc adv surg Tech 2003, 13:11-15.

16. Mathevet P, Nessah K, Dargent D, Mellier G: Laparoscopic management of adnexal masses in pregnancy: a case series. Eur J Obstet gynecol reprod Biol 2003;108:217-22.

17. Yuen PM, Ng PS, Leung PL, Rogers MS: Outcome in laparoscopic management of persistent adnexal mass during the second trimester of pregnancy. Surg Endosc 2004; 18:1354-7.

18. Ni Mhuireachtaigh R, O'Gorman DA: Anesthesia in pregnant women for non-obstetric surgery. J Clin Anesth 2006, 18:60-66.

19. R.P. Masand, E.D. Euscher, M.T. Deavers, A. Malpica, Endometrioidstromalsarcoma: a clinicopathologic study of 63 cases, Am J Surg Pathol 37(2013)1635-47.

20. A. Zemlyak, S. Hwang, E. Chalas, C.R.J. Pameijer, Primary extrauterineendometrial stromal cell sarcoma: a case and review, J. Gastrointest. Cancer 39(2008):104-106,

21. J.A. Rauh-Hain, M.G. del Carmen, Endometrial stromal sarcoma: a systematicreview, Obstet Gynecol 122(2013):676-683,

22. Thigpen JT, Brady MF, Alvarez RD, Adelson MD, Homesley HD, Manetta A et al. Oral medroxyprogesterone acetate in the treatment of advanced or recurrent endometrial carcinoma: a dose-response study by the Gynecologic Oncology Group. J Clin Oncol 1999;17:173644

23. Goff BA, Rice LW, Fleischhacker D. Uterine leiomyosarcoma and endometrial stromal sarcoma: Lymph node metastases and sites of recurrence. Gynecoloncol 1993;50:105-9.

24. Sutton G, Blessing JA, Park R, disaia PJ, Rosenshein N. Ifosfamide treatment of recurrent or metastatic endometrial stromal sarcomas previously unexposed to chemotherapy: A study of the Gynecologic Oncology Group. Obstetgynecol 1996;87:747-50.

25. Li N, Wu LY, Zhang HT, An JS, Li XG, Ma SK et al. Treatment options in stage Iendometrial stromal sarcoma: a retrospective analysis of 53 cases. Gynecol Oncol 2008;108(2):306-11.

26. Chu MC, Mor G, Lim C, Zheng W, Parkash V, Schwartz PE et al. Low-grade endome-trial stromal sarcoma: hormonal aspects. Gynecoloncol 2003;90(1):170-6.

27. Reerink EH, Scholer HF, Westerhof P, Querido A, Kassenaar AA, Diczfalusy E et al. A new class of hormonally active steroids. Nat 1960;186:168-9.

28. Schindler AE. Progestational effects of dydrogesterone in vitro, in vivo and on the human endometrium. Maturitas 2009;65Suppl 1:S3-11.

29. Sugimoto AK, Hodsman AB, Nisker JA. Long-term gonadotropinreleasing hormone agonist with standard 
postmenopausal estrogen replacement failed to prevent vertebral bone loss in premenopausalwomen. Fertilsteril 1993;60:672-4.

30. Paoletti AM, Serra GG, Cagnacci A, Vacca AM, Guerriero $\mathrm{S}$, Solla E et al. Spontaneous reversibility of bone loss induced by gonadotropin- releasing hormone analog treatment. Fertilsteril 1996; 65:707-10.

31. Maluf FC, Sabbatini P, Schwartz L, Xia J, Aghajanian C. Endometrial stromal sarcoma: objective response to letrozole. Gynecoloncol 2001;82:384-8.

32. Fontein DB, Nortier JW, Liefers GJ, Putter H, MeershoekKlein Kranenbarg E, van den Bosch J, et al. High noncompliance in the use of letrozole after 2.5 years of extended adjuvant endocrine therapy. Results from the IDEAL randomized trial. Eur J surgoncol 2012;38:110-7.
33. Fontein DB, Nortier JW, Liefers GJ, Putter H, MeershoekKlein Kranenbarg E, van den Bosch J et al. High noncompliance in the use of letrozole after 2.5 years of extended adjuvant endocrine therapy. Results from the IDEAL randomized trial. Eur J Surg Oncol 2012;38:110-7.

34. Chan JK, Kawar NM, Shin JY. Endometrial stromal sarcoma: A population-based analysis. Br J Cancer 2008;99:1210-5.

How to cite this article: Geetha, Rathika R, Endometrial stromal sarcoma- A case report. Indian J Obstet Gynecol Res 2019;6(2):225-227. 